\title{
Comparative analysis between SINAPI's indexes and those adopted by the companies of the city of Manaus in the services of concrete production and frame
}

\author{
Daniel Damião Almeida de Almeida ${ }^{1}$, Willace Lima de Souza ${ }^{2}$, Darlei dos Anjos Lavor ${ }^{3}$ \\ ${ }^{1,2,3}$ Centro Universitário do Norte (UniNorte) - Laureate International Universities - Manaus-AM. \\ Email: engdanieldamiao@gmail.com; willace.souza@uninorte.com.br; darleilavor27@gmail.com
}

Received: nOVEMBER $28^{\text {th }}, 2017$.

Accepted: January $08^{\text {th }}, 2018$.

Published: March $30^{\text {th }}, 2018$.

Copyright (C2016 by authors and Institute of Technology Galileo of Amazon (ITEGAM).

This work is licensed under the Creative Commons Attribution International

License (CC BY 4.0).

http://creativecommons.org/licenses/by/4.0/

(c) (i) (3) Open Actes:

\begin{abstract}
In the present study, a comparative analysis between the SINAPI's indexes and those adopted by companies of the city of Manaus-AM is presented, in the services of concrete production and frame. The differences between the indexes and the economic impact caused by them were verified, through budgetary simulation with data from State Secretariat of Infrastructure of Amazonas, where was attested the viability of using the SINAPI values only to the inputs defined as materials, while those referring to labor and equipment, according to this research, need greater care because they present significant differences between the costs studied, safety, control and management, communications, accessibility and the building's life cycle.
\end{abstract}

Keywords: Budgets, Compositions, Indexes, Concrete, Frame.

\section{Análise comparativa entre os índices aferidos pelo SINAPI e os adotados por empresas da cidade de Manaus nos serviços de produção de concreto e armação}

\begin{abstract}
RESUMO
No presente estudo, é apresentada uma análise comparativa entre os índices adotados pelo SINAPI e por empresas da cidade de Manaus-AM, nos serviços de produção de concreto e armação. Foram verificadas as diferenças percentuais entre os índices e o impacto econômico provocados pelos mesmos, através de simulação orçamentária com dados da Secretaria de Estado de Infraestrutura do Amazonas, onde atestou-se a viabilidade da utilização dos valores do SINAPI apenas no tocante aos insumos caracterizados como materiais, enquanto aqueles referentes à mão de obra e equipamentos, de acordo com esta pesquisa, necessitam de maiores cuidados por apresentarem significativas diferenças entre os custos estudados.
\end{abstract}

Palavras Chaves: Orçamentos, Composições, Índices, Concreto, Armação.

\section{INTRODUÇÃO}

No setor da construção civil, diante de um mercado competitivo que engloba as empresas nos dias atuais, um planejamento preciso, detalhado e que represente fidedignamente a realidade da obra é primordial para a elaboração do orçamento final que atenda as exigências do cliente, ao assegurar a qualidade final do produto, assim como os exigentes cronogramas.

Muitos são os itens que influenciam e contribuem para o custo de um empreendimento, a fim de cumprir, principalmente, o prazo da obra. Dentre estes itens, está a produtividade, correspondente à taxa de produção dos operários e equipamentos e o consumo dos materiais para a execução de determinado serviço, ou seja, a quantidade de unidades de trabalho produzida em um intervalo de tempo [1].

O planejamento de uma obra se constitui em um dos principais aspectos do gerenciamento, onde engloba-se orçamento, suprimentos, produtividade, relações interpessoais, comunicação, tecnologia, infraestrutura, etc. [2]. Nesse sentido, o levantamento dos custos é a primeira ação a ser empreendida para determinar a realização ou não de um empreendimento e o montante a ser investido, para limitar o vulto da obra e, até mesmo, para definir as especificações da mesma [3].

Ressalta-se que para a elaboração das composições de custo unitário, definidas como o processo de estabelecimento dos 
custos incorridos para a execução de um serviço ou atividade, discriminados por insumo, como mão de obra, materiais e equipamentos, considera-se a utilização de índices, caracterizados por ser o inverso da produtividade, ou seja, a incidência de cada insumo na execução de uma unidade de serviço [1][4].

Para a construção de composições de custo unitário, existem inúmeras tabelas para referência, dentre elas a da PINI, apresentadas na TCPO - Tabela de Composição e Preços para Orçamentos, que é uma das que mais se aproximam da realidade da obra [5].

Ademais, também são utilizadas as tabelas do SINAPI Sistema Nacional de Pesquisas de Custos e Índices da Construção Civil, que de forma geral, segundo a Caixa Econômica Federal, estabelece regras e diretrizes para construção do orçamento de referência de obras e serviços de engenharia, contratados e executados com recursos dos orçamentos da União, para obtenção de referência de custo, e pela Lei 13.303/2016 [6].

Desta forma, o presente estudo tem como intento a análise dos coeficientes aferidos pelo SINAPI, em comparação aos adotados por empresas da Cidade de Manaus, no que se refere aos serviços de produção de concreto e de armação de estruturas de concreto armado.

\section{METODOLOGIA}

A metodologia aplicada neste trabalho consiste na análise da viabilidade da utilização dos coeficientes aferidos pelo SINAPI para a elaboração de orçamento de obras verticais na cidade de Manaus, no âmbito privado, com ênfase nas composições de custo unitário dos serviços de produção de concreto e de armação de estruturas de concreto armado.

\section{II.1 PREMISSAS TÉCNICAS}

Neste caso, o método de pesquisa caracterizou-se pela execução de seis etapas, conforme disposto na Figura 1, onde por fim, através de uma simulação orçamentária, foi possível avaliar de forma contábil, as diferenças existentes entre os índices adotados por empresas da cidade de Manaus e pela Caixa Econômica Federal (CEF), em conjunto com o Instituto Brasileiro de Geografia e Estatística (IBGE).

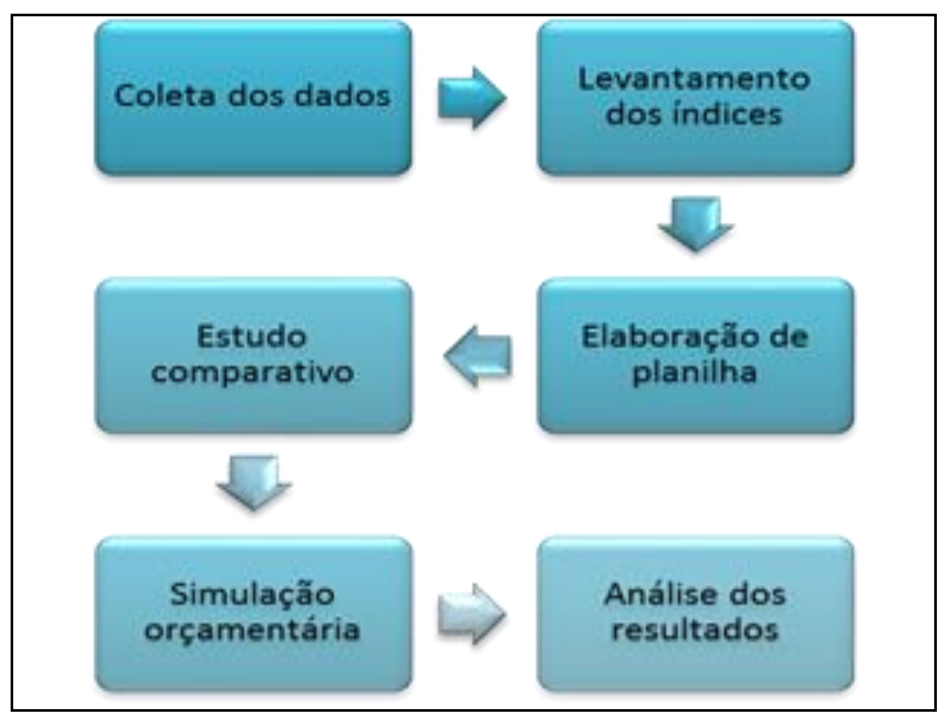

Figura 1: Fluxograma das etapas adotadas nesta pesquisa.

Fonte: Autores, (2017).

\section{II.2 COLETA DOS DADOS}

Inicialmente, para a realização desta pesquisa, foram coletados orçamentos junto a quatro empresas de pequeno e médio porte da cidade de Manaus, que não utilizavam tabelas de referência para a elaboração de composições de custo unitário para serviços de obras verticais e que, além disso, adotavam os índices conforme a experiência adquirida ao longo do tempo na construção civil, assim como em função do conhecimento da produtividade da mão de obra e equipamentos.

Em seguida, foram consultados os cadernos técnicos referentes aos serviços de produção de concreto e armação de estruturas de concreto armado, disponibilizados pela CEF, onde os mesmos, além de exibirem os insumos da composição e suas características, também apresentam os processos para quantificação do serviço, critérios de aferição, normas técnicas, dentre outros fatores que permitem a seleção dos índices com segurança.

\section{II.3 LEVANTAMENTO DOS ÍNDICES}

Após a coleta dos dados, foi realizado o levantamento dos índices através das composições de custo unitário disponibilizadas pelas quatro empresas da cidade de Manaus, assim como dos cadernos técnicos do SINAPI, onde discriminouse os insumos em materiais, mão de obra e equipamentos. Ressalta-se que, quanto à mão de obra envolvida nos serviços, foram adotados os índices cujos encargos sociais apresentavam-se inclusos.

No caso do serviço de produção de concreto, foi considerada a composição que apresentava a utilização de betoneira com capacidade de 400 litros e a resistência característica à compressão $\left(\mathrm{f}_{\mathrm{ck}}\right)$ igual a $25 \mathrm{MPa}$, caracterizando-o como concreto estrutural, conforme ilustrado na Figura 2.

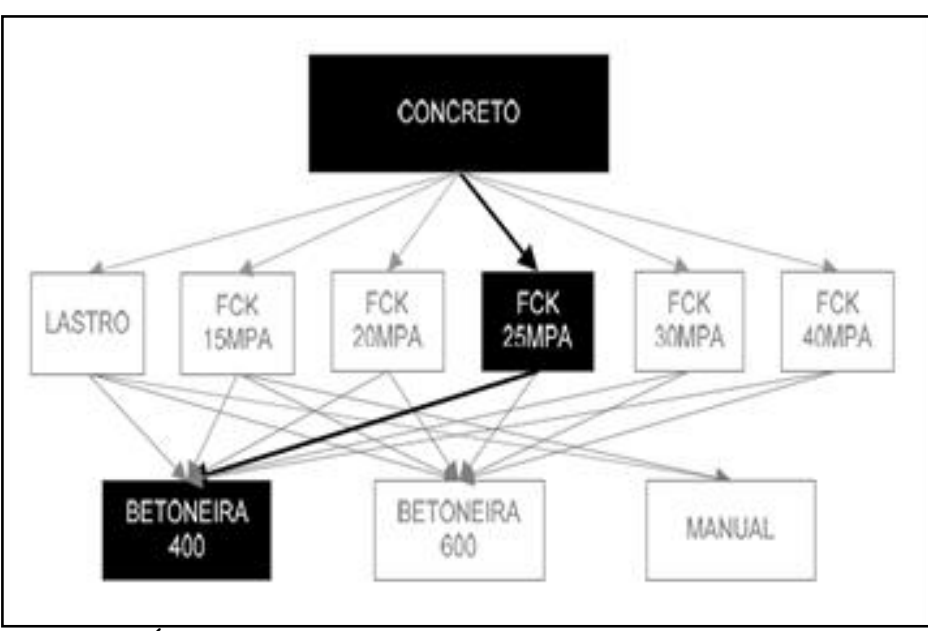

Figura 2: Árvore de fatores do serviço de produção do concreto. Fonte: SINAPI (caderno técnico), (2017).

Para o serviço de armação de estruturas de concreto armado, foi considerada a composição que utilizava o aço CA50A, onde o mesmo, para o caso das empresas, é aplicado para todas as bitolas e elementos estruturais. No tocante ao caderno técnico do SINAPI que trata sobre as armações, verificou-se que são apresentados índices conforme a dimensão da bitola e a aplicação estrutural (lajes, vigas e pilares) e por isso, consideraram-se os diâmetros em que os índices proporcionariam um menor e um maior impacto no custo na obra. 
Desta forma, foram utilizadas as bitolas de diâmetro igual $20 \mathrm{~mm}$ e $6,3 \mathrm{~mm}$, com a aplicação em lajes de concreto armado, em função de apresentarem, respectivamente, menor e maior relevância do ponto de vista econômico.

Ademais, foi obtida a média aritmética entre os índices dos insumos apresentados pelo caderno técnico para a execução de armação de estruturas de concreto armado, onde englobam-se todos os diâmetros, tanto para lajes, como para vigas e pilares, a fim de avaliar a proximidade destes valores médios em relação aos adotados pelas empresas.

\section{II.4 ELABORAÇÃO DE PLANILHA}

Posteriormente ao levantamento dos índices, foi elaborada uma planilha com auxílio do programa computacional Microsoft Office Excel 2016, no intento de permitir uma análise mais refinada em relação aos valores em estudo, de forma a verificar as similaridades ou diferenças existentes entre eles.

\section{II.5 ESTUDO COMPARATIVO}

A partir da planilha de índices, foi realizada uma análise comparativa percentual entre as empresas e o SINAPI, em relação a cada insumo que compõe os serviços em estudo, a fim de avaliar os seguintes aspectos:

- Diferenças entre as empresas;

- Diferenças das empresas em relação à média aritmética e o SINAPI;

- Cenário da cidade de Manaus no tocante à produtividade.

\section{II.6 SIMULAÇÃO ORÇAMENTÁRIA}

No intuito da visualização do impacto dos índices quanto ao âmbito financeiro, foi realizada uma simulação orçamentária para cada uma das quatro empresas em estudo e para o SINAPI, onde consideraram-se os custos unitários utilizados pela Secretaria de Estado de Infraestrutura do Amazonas (SEINFRA$\mathrm{AM}$ ), a fim de se obter uma maior proximidade à realidade local.

Neste caso, optou-se pela não utilização do BDI, em virtude de não proporcionar diferenças relevantes, e por ser possível a análise dos resultados apenas com os valores de índices e custos unitários referentes aos insumos que compreendem os serviços de produção de concreto e armação de estruturas de concreto armado.

\section{II.7 ANÁLISE DOS RESULTADOS}

Com posse dos resultados obtidos através da simulação orçamentária, realizou-se uma análise comparativa contábil, representada percentualmente e graficamente, no intuito de verificar as diferenças existentes entre os valores adotados pelas empresas e pelo o que é proposto pela Caixa Econômica Federal, e a viabilidade da utilização das tabelas de referência do SINAPI para elaboração de orçamentos de obras na cidade de Manaus.

\section{RESULTADOS E DISCUSSÕES}

Os resultados obtidos nesta pesquisa, assim como descrito na metodologia, apresentam uma série de observações em relação à viabilidade da utilização dos coeficientes aferidos pelo SINAPI para a elaboração de orçamento de obras verticais na cidade de Manaus, no que se refere aos serviços de produção de concreto e armação de estruturas de concreto armado, onde destaca-se que para o primeiro serviço, é considerada a utilização de betoneira com capacidade de 400 litros e o $\mathrm{f}_{\text {ck }}$ igual a $25 \mathrm{MPa}$, e para o segundo, adotou-se a utilização do aço CA-50A.

\section{III.1 ÍNDICES DOS SERVIÇOS}

A Tabela 1 apresenta os valores de índices que são adotados pelas quatro empresas envolvidas no estudo, assim como a média aritmética das mesmas e os aferidos pelo sistema da CEF, para os insumos que compõem o serviço de produção de concreto.

Tabela 1: Índices do serviço de produção de concreto.

\begin{tabular}{|l|l|l|l|l|l|l|}
\hline $\begin{array}{l}\text { CONCRETO } \\
\text { ESTRUTURAL }\end{array}$ & $\mathrm{A}$ & $\mathrm{B}$ & $\mathrm{C}$ & $\mathrm{D}$ & Média & SINAPI \\
\cline { 2 - 6 } & & & & & & \\
\hline $\begin{array}{l}\text { Cimento } \\
\text { Portland }\end{array}$ & 365,0 & 400,0 & 350,0 & 351,7647 & 366,6911 & 362,66 \\
\hline Areia & 0,830 & 0,6 & 0,6 & 0,61394 & 0,66099 & 0,751 \\
\hline Brita & 0,840 & 0,5 & 0,5 & 0,87816 & 0,67954 & 0,593 \\
\hline Pedreiro & 2,0 & 3,0 & 3,0 & 3,19992 & 2,79998 & 1,46 \\
\hline Servente & 8,0 & 8,0 & 8,0 & 4,80008 & 7,20002 & 2,31 \\
\hline $\begin{array}{l}\text { Betoneira } \\
\text { (400 litros) }\end{array}$ & 0,036 & 0,040 & 0,038 & 0,70693 & 0,20523 & 0,750 \\
\hline
\end{tabular}

Fonte: Autores, (2017).

A princípio, percebe-se que os valores correspondentes aos materiais (Cimento Portland, areia e brita) apresentam diferenças mínimas quando comparados entre as empresas e o SINAPI. Porém, em relação à mão de obra (pedreiro e servente), nota-se que os valores adotados pelas empresas da cidade de Manaus distanciam-se dos valores aferidos pela CEF, assim como acontece no que se trata ao insumo referente aos equipamentos (betoneira), onde apenas a Empresa D se aproxima do valor estabelecido pelo SINAPI.

Nas Tabelas 2 e 3, são destacados os índices dos insumos que compõem o serviço de armação de estruturas de concreto armado.

Tabela 2: Índices do serviço de armação (Empresas).

\begin{tabular}{|l|l|l|l|l|}
\hline ARMAÇÃO & $\begin{array}{l}\text { Empresa } \\
\text { A }\end{array}$ & $\begin{array}{l}\text { Empresa } \\
\text { B }\end{array}$ & $\begin{array}{l}\text { Empresa } \\
\text { C }\end{array}$ & $\begin{array}{l}\text { Empresa } \\
\text { D }\end{array}$ \\
\hline $\begin{array}{l}\text { Aço CA-50 } \\
\begin{array}{l}\text { Arame Recozido N } \\
18\end{array}\end{array}$ & 1,05 & 1,00 & 1,00 & 1,1007633 \\
\hline $\begin{array}{l}\text { Espaçador Circular } \\
\text { de Plástico }\end{array}$ & 11,70 & 1,35 & 1,32 & 1,32 \\
\hline $\begin{array}{l}\text { Armador } \\
\text { Ajudante de } \\
\text { Armador }\end{array}$ & 0,07 & 0,13 & 0,13 & 0,06416 \\
\hline
\end{tabular}

Fonte: Autores, (2017). 
Tabela 3: Índices do serviço de armação (Média e SINAPI).

\begin{tabular}{|l|l|l|l|l|}
\hline \multirow{2}{*}{ ARMAÇÃO } & Média & das & \multicolumn{3}{|l|}{ SINAPI } \\
\cline { 4 - 6 } & Empresas & $\begin{array}{l}\text { Menor } \\
\text { Valor }\end{array}$ & $\begin{array}{l}\text { Maior } \\
\text { Valor }\end{array}$ & $\begin{array}{l}\text { Média } \\
\text { Geral }\end{array}$ \\
\hline $\begin{array}{l}\text { Aço CA-50 } \\
\begin{array}{l}\text { Arame Recozido } \\
\mathbf{N}^{\circ} 18\end{array}\end{array}$ & 1,03769 & 1,00 & 1,00 & 1,00 \\
\hline $\begin{array}{l}\text { Espaçador } \\
\text { Circular } \\
\text { Plástico }\end{array}$ & 0,02523 & 0,025 & 0,025 & 0,025 \\
\hline $\begin{array}{l}\text { Armador } \\
\text { Ajudante } \\
\text { Armador }\end{array}$ & 3,92250 & 0,010 & 1,333 & 0,4321 \\
\hline
\end{tabular}

Fonte: Autores, (2017).

Preliminarmente, foi evidenciado que no caso dos valores aferidos pelo SINAPI, os índices correspondentes ao aço CA-50 e ao arame recozido $n^{\circ} 18$ não apresentam diferenças em função do diâmetro do aço e da aplicação estrutural. Dessa forma, os índices pertencentes aos menores e maiores valores, assim como à média geral, caracterizam-se por serem iguais, conforme apresentado na Tabela 3.

Com base nisso, observa-se que os índices referentes aos insumos da classe dos materiais apontam proximidade quando comparados em função das empresas e do maior valor disponibilizado pelo CEF, exceto para o caso da Empresa A no insumo correspondente ao espaçador circular de plástico, onde o valor apresentado se difere expressivamente em relação aos demais.

Por fim, assim como ocorrido quanto ao serviço de produção de concreto, os valores de índices estabelecidos para os insumos referentes à mão de obra do serviço de armação de estruturas de concreto armado, que são adotados pelas empresas, distanciam-se do que é sugerido pelo SINAPI, exceto no tocante ao índice da Empresa D correspondente ao armador, onde nesta situação, apresenta-se um valor próximo quando comparado ao maior valor aferido pelo sistema da CEF.

\section{III.2 ESTUDO COMPARATIVO ENTRE OS ÍNDICES}

No intento de exibir o quanto cada empresa se difere em relação às demais, a Tabela 4 permite, através de uma análise percentual entre os valores obtidos por intermédio da planilha de índices, destacar as seguintes observações quanto ao serviço de produção de concreto:

- Em relação ao cimento Portland, os índices adotados pelas empresas sempre demonstram proximidade entre os valores;

- Quanto à mão de obra, os valores atribuídos ao servente são afins, exceto para a Empresa D;

- A Empresa B apresenta valores próximos e muitas vezes iguais comparados aos adotados pela Empresa $\mathrm{C}$;

- A Empresa D, no que se refere ao insumo betoneira, apresenta uma diferença superior a $1700,00 \%$ em relação às demais empresas.
Tabela 4: Análise percentual dos índices de produção de concreto (Empresas).

\begin{tabular}{|l|l|l|l|}
\hline Empresa A & Empresa B & Empresa C & Empresa D \\
\hline Cimento Portland & $91,25 \%$ & $104,29 \%$ & $103,76 \%$ \\
\hline Areia & $138,33 \%$ & $138,33 \%$ & $135,19 \%$ \\
\hline Brita & $168,00 \%$ & $168,00 \%$ & $95,65 \%$ \\
\hline Pedreiro & $66,67 \%$ & $66,67 \%$ & $62,50 \%$ \\
\hline Servente & $100,00 \%$ & $100,00 \%$ & $166,66 \%$ \\
\hline Betoneira & $90,00 \%$ & $94,74 \%$ & $5,09 \%$ \\
\hline Empresa B & Empresa A & Empresa C & Empresa D \\
\hline Cimento Portland & $109,59 \%$ & $114,29 \%$ & $113,71 \%$ \\
\hline Areia & $72,29 \%$ & $100,00 \%$ & $97,73 \%$ \\
\hline Brita & $59,52 \%$ & $100,00 \%$ & $56,94 \%$ \\
\hline Pedreiro & $150,00 \%$ & $100,00 \%$ & $93,75 \%$ \\
\hline Servente & $100,00 \%$ & $100,00 \%$ & $166,66 \%$ \\
\hline Betoneira & $111,11 \%$ & $105,26 \%$ & $5,66 \%$ \\
\hline Empresa C & Empresa A & Empresa B & Empresa D \\
\hline Cimento Portland & $95,89 \%$ & $87,50 \%$ & $99,50 \%$ \\
\hline Areia & $72,29 \%$ & $100,00 \%$ & $97,73 \%$ \\
\hline Brita & $59,52 \%$ & $100,00 \%$ & $56,94 \%$ \\
\hline Pedreiro & $150,00 \%$ & $100,00 \%$ & $93,75 \%$ \\
\hline Servente & $100,00 \%$ & $100,00 \%$ & $166,66 \%$ \\
\hline Betoneira & $105,56 \%$ & $95,00 \%$ & $5,38 \%$ \\
\hline Empresa D & Empresa A & Empresa B & Empresa C \\
\hline Cimento Portland & $96,37 \%$ & $87,94 \%$ & $100,50 \%$ \\
\hline Areia & $73,97 \%$ & $102,32 \%$ & $102,32 \%$ \\
\hline Brita & $104,54 \%$ & $175,63 \%$ & $175,63 \%$ \\
\hline Pedreiro & $160,00 \%$ & $106,66 \%$ & $106,66 \%$ \\
\hline Servente & $60,00 \%$ & $60,00 \%$ & $60,00 \%$ \\
\hline Betoneira & $1963,69 \%$ & $1767,33 \%$ & $1860,34 \%$ \\
\hline
\end{tabular}

Fonte: Autores, (2017).

Logo, observa-se que para o serviço de produção de concreto, a Empresa $\mathrm{C}$ é a que mais se aproxima em relação às demais e a Empresa D é a que mais se distancia, principalmente em função da expressiva diferença ocasionada pelo insumo betoneira. Porém, de maneira geral, as empresas apresentam poucas diferenças entre si no tocante aos valores que são adotados para os insumos que fazem parte da composição deste serviço.

De forma análoga à apresentada anteriormente, a Tabela 5 apresenta os valores obtidos através da análise percentual entre os índices do serviço de armação de estruturas de concreto armado. 
Tabela 5: Análise percentual dos índices de armação.

\begin{tabular}{|c|c|c|c|}
\hline Empresa A & Empresa B & Empresa C & Empresa D \\
\hline Aço CA-50 & $105,00 \%$ & $105,00 \%$ & $95,39 \%$ \\
\hline Arame Recozido $N^{\circ} 18$ & $66,67 \%$ & $66,67 \%$ & $95,56 \%$ \\
\hline $\begin{array}{l}\text { Espaçador Circular de } \\
\text { Plástico }\end{array}$ & $866,67 \%$ & $886,36 \%$ & $886,36 \%$ \\
\hline Armador & $53,85 \%$ & $53,85 \%$ & $109,10 \%$ \\
\hline Ajudante de Armador & $53,85 \%$ & $53,85 \%$ & $107,92 \%$ \\
\hline Empresa B & Empresa A & Empresa C & Empresa D \\
\hline Aço CA-50 & $95,24 \%$ & $100,00 \%$ & $90,85 \%$ \\
\hline Arame Recozido $\mathrm{N}^{\circ} 18$ & $150,00 \%$ & $100,00 \%$ & $143,33 \%$ \\
\hline $\begin{array}{l}\text { Espaçador Circular de } \\
\text { Plástico }\end{array}$ & $11,54 \%$ & $102,27 \%$ & $102,27 \%$ \\
\hline Armador & $185,71 \%$ & $100,00 \%$ & $202,62 \%$ \\
\hline Ajudante de Armador & $185,71 \%$ & $100,00 \%$ & $200,43 \%$ \\
\hline Empresa C & Empresa A & Empresa B & Empresa D \\
\hline Aço CA-50 & $95,24 \%$ & $100,00 \%$ & $90,85 \%$ \\
\hline Arame Recozido $N^{\circ} 18$ & $150,00 \%$ & $100,00 \%$ & $143,33 \%$ \\
\hline $\begin{array}{l}\text { Espaçador Circular de } \\
\text { Plástico }\end{array}$ & $11,28 \%$ & $97,78 \%$ & $100,00 \%$ \\
\hline Armador & $185,71 \%$ & $100,00 \%$ & $202,62 \%$ \\
\hline Ajudante de Armador & $185,71 \%$ & $100,00 \%$ & $200,43 \%$ \\
\hline Empresa D & Empresa A & Empresa B & Empresa C \\
\hline Aço CA-50 & $104,83 \%$ & $110,08 \%$ & $110,08 \%$ \\
\hline Arame Recozido $N^{\circ} 18$ & $104,65 \%$ & $69,77 \%$ & $69,77 \%$ \\
\hline $\begin{array}{l}\text { Espaçador Circular de } \\
\text { Plástico }\end{array}$ & $11,28 \%$ & $97,78 \%$ & $100,00 \%$ \\
\hline Armador & $91,66 \%$ & $49,35 \%$ & $49,35 \%$ \\
\hline Ajudante de Armador & $92,66 \%$ & $49,89 \%$ & $49,89 \%$ \\
\hline
\end{tabular}

Fonte: Autores, (2017).

Neste caso, constatam-se as seguintes observações a respeito dos resultados obtidos pela tabela acima:

- Os insumos referentes ao aço CA-50 e arame recozido $n^{\circ}$ 18 apresentam proximidade entre os valores adotados pelas empresas;

- A Empresa B apresenta valores iguais aos adotados pela Empresa C, exceto no insumo referente ao espaçador circular de plástico, onde há uma diferença inferior a $3 \%$;

- A Empresa A apresenta uma diferença de 866,67\% em relação às demais empresas no que se refere ao espaçador circular de plástico.

Portanto, de forma geral, é possível verificar que a Empresa D é a que mais se aproxima em relação às demais, enquanto a Empresa A é a que mais se difere, em virtude da expressiva diferença, em relação aos adotados pelas empresas, do valor do índice correspondente ao espaçador circular de plástico. Desta forma, pode-se considerar que para a maioria dos insumos que fazem parte da composição do serviço de armação de estruturas de concreto armado, as empresas apresentam poucas diferenças entre si.
No que se refere ao comportamento dos índices adotados pelas empresas em relação à média aritmética e ao SINAPI, as Tabela 6 e 7 apontam, respectivamente, as diferenças percentuais existentes entre os insumos que compõem o serviço de produção de concreto e o de armação de estruturas de concreto armado.

Tabela 6: Análise percentual dos índices de produção de concreto (Média e SINAPI).

\begin{tabular}{|l|l|l|}
\hline Empresa A & Média das Empresas & SINAPI \\
\hline Cimento Portland & $99,54 \%$ & $100,65 \%$ \\
\hline Areia & $125,57 \%$ & $110,52 \%$ \\
\hline Brita & $123,61 \%$ & $141,65 \%$ \\
\hline Pedreiro & $71,43 \%$ & $136,99 \%$ \\
\hline Servente & $111,11 \%$ & $346,32 \%$ \\
\hline Betoneira & $17,54 \%$ & $4,80 \%$ \\
\hline Empresa B & Média das Empresas & SINAPI \\
\hline Cimento Portland & $109,08 \%$ & $110,30 \%$ \\
\hline Areia & $90,77 \%$ & $79,89 \%$ \\
\hline Brita & $73,58 \%$ & $84,32 \%$ \\
\hline Pedreiro & $107,14 \%$ & $205,48 \%$ \\
\hline Servente & $111,11 \%$ & $346,32 \%$ \\
\hline Betoneira & $19,49 \%$ & $5,33 \%$ \\
\hline Empresa C & Média das Empresas & SINAPI \\
\hline Cimento Portland & $95,45 \%$ & $96,51 \%$ \\
\hline Areia & $90,77 \%$ & $79,89 \%$ \\
\hline Brita & $73,58 \%$ & $84,32 \%$ \\
\hline Pedreiro & $107,14 \%$ & $205,48 \%$ \\
\hline Servente & $111,11 \%$ & $346,32 \%$ \\
\hline Betoneira & $18,52 \%$ & $5,07 \%$ \\
\hline Empresa D & Média das Empresas & SINAPI \\
\hline Cimento Portland & $95,93 \%$ & $97,00 \%$ \\
\hline Areia & $92,88 \%$ & $81,75 \%$ \\
\hline Brita & $129,23 \%$ & $148,09 \%$ \\
\hline Pedreiro & $114,28 \%$ & $219,17 \%$ \\
\hline Servente & $66,67 \%$ & \\
\hline Betoneira & $344,45 \%$ & \\
\hline Eont: Autores $\%$ & \\
\hline
\end{tabular}

Fonte: Autores, (2017).

Neste contexto, observa-se que para o serviço de produção de concreto, a Empresa $C$ é a que mais se aproxima da média das empresas, enquanto a Empresa D é a que mais distancia, assim como confirmado anteriormente quando analisadas as porcentagens entre as empresas.

Quando comparadas aos valores aferidos pelo SINAPI, percebe-se que do mesmo modo que acontece na análise entre as médias das empresas, a Empresa $\mathrm{C}$ é a que mais se aproxima dentre os índices apresentados, enquanto a Empresa D é a que mais de difere. 
Tabela 7: Análise percentual dos índices de armação (Média e SINAPI).

\begin{tabular}{|c|c|c|c|c|}
\hline \multirow[b]{2}{*}{ Empresa A } & \multirow{2}{*}{$\begin{array}{l}\text { Média das } \\
\text { Empresas }\end{array}$} & \multicolumn{3}{|l|}{ SINAPI } \\
\hline & & $\begin{array}{l}\text { Menor } \\
\text { Valor }\end{array}$ & $\begin{array}{l}\text { Maior } \\
\text { Valor }\end{array}$ & $\begin{array}{l}\text { Média } \\
\text { Geral }\end{array}$ \\
\hline Aço CA-50 & $101,19 \%$ & $105,00 \%$ & $105,00 \%$ & $105,00 \%$ \\
\hline $\begin{array}{l}\text { Arame } \\
\text { Recozido } \mathrm{N}^{\circ} \\
18\end{array}$ & $79,26 \%$ & $80,00 \%$ & $80,00 \%$ & $80,00 \%$ \\
\hline $\begin{array}{l}\text { Espaçador } \\
\text { Circular de } \\
\text { Plástico }\end{array}$ & $298,28 \%$ & $117000,00 \%$ & $877,72 \%$ & $2707,71 \%$ \\
\hline Armador & $71,04 \%$ & $744,68 \%$ & $108,36 \%$ & $179,49 \%$ \\
\hline $\begin{array}{l}\text { Ajudante de } \\
\text { Armador }\end{array}$ & $70,91 \%$ & $4666,67 \%$ & $666,67 \%$ & $1093,75 \%$ \\
\hline \multirow[b]{2}{*}{ Empresa B } & \multirow{2}{*}{$\begin{array}{l}\text { Média das } \\
\text { Empresas }\end{array}$} & \multicolumn{3}{|l|}{ SINAPI } \\
\hline & & $\begin{array}{l}\text { Menor } \\
\text { Valor }\end{array}$ & $\begin{array}{l}\text { Maior } \\
\text { Valor }\end{array}$ & $\begin{array}{l}\text { Média } \\
\text { Geral }\end{array}$ \\
\hline Aço CA-50 & $96,37 \%$ & $100,00 \%$ & $100,00 \%$ & $100,00 \%$ \\
\hline $\begin{array}{l}\text { Arame } \\
\text { Recozido } \mathrm{N}^{\circ} \\
18\end{array}$ & $118,89 \%$ & $120,00 \%$ & $120,00 \%$ & $120,00 \%$ \\
\hline $\begin{array}{l}\text { Espaçador } \\
\text { Circular de } \\
\text { Plástico }\end{array}$ & $34,42 \%$ & $13500,00 \%$ & $101,28 \%$ & $312,43 \%$ \\
\hline Armador & $131,93 \%$ & $1382,98 \%$ & $201,24 \%$ & $333,33 \%$ \\
\hline $\begin{array}{l}\text { Ajudante de } \\
\text { Armador }\end{array}$ & $131,69 \%$ & $8666,67 \%$ & $1238,10 \%$ & $2031,25 \%$ \\
\hline \multirow[b]{2}{*}{ Empresa C } & \multirow{2}{*}{$\begin{array}{l}\text { Média das } \\
\text { Empresas }\end{array}$} & \multicolumn{3}{|l|}{ SINAPI } \\
\hline & & $\begin{array}{l}\text { Menor } \\
\text { Valor }\end{array}$ & $\begin{array}{l}\text { Maior } \\
\text { Valor }\end{array}$ & $\begin{array}{l}\text { Média } \\
\text { Geral }\end{array}$ \\
\hline Aço CA-50 & $96,37 \%$ & $100,00 \%$ & $100,00 \%$ & $100,00 \%$ \\
\hline $\begin{array}{l}\text { Arame } \\
\text { Recozido } \mathrm{N}^{\circ} \\
18\end{array}$ & $118,89 \%$ & $120,00 \%$ & $120,00 \%$ & $120,00 \%$ \\
\hline $\begin{array}{l}\text { Espaçador } \\
\text { Circular de } \\
\text { Plástico }\end{array}$ & $33,65 \%$ & $13200,00 \%$ & $99,02 \%$ & $305,48 \%$ \\
\hline Armador & $131,93 \%$ & $1382,98 \%$ & $201,24 \%$ & $333,33 \%$ \\
\hline $\begin{array}{l}\text { Ajudante de } \\
\text { Armador }\end{array}$ & $131,69 \%$ & $8666,67 \%$ & $1238,10 \%$ & $2031,25 \%$ \\
\hline \multirow[b]{2}{*}{ Empresa D } & \multirow{2}{*}{$\begin{array}{l}\text { Média das } \\
\text { Empresas }\end{array}$} & \multicolumn{3}{|l|}{ SINAPI } \\
\hline & & $\begin{array}{l}\text { Menor } \\
\text { Valor }\end{array}$ & $\begin{array}{l}\text { Maior } \\
\text { Valor }\end{array}$ & $\begin{array}{l}\text { Média } \\
\text { Geral }\end{array}$ \\
\hline Aço CA-50 & $106,08 \%$ & $110,08 \%$ & $110,08 \%$ & $110,08 \%$ \\
\hline $\begin{array}{l}\text { Arame } \\
\text { Recozido } \mathrm{N}^{\circ} \\
18\end{array}$ & $82,95 \%$ & $83,72 \%$ & $83,72 \%$ & $83,72 \%$ \\
\hline $\begin{array}{l}\text { Espaçador } \\
\text { Circular de } \\
\text { Plástico }\end{array}$ & $33,65 \%$ & $13200,00 \%$ & $99,02 \%$ & $305,48 \%$ \\
\hline Armador & $65,11 \%$ & $682,55 \%$ & $99,32 \%$ & $164,51 \%$ \\
\hline $\begin{array}{l}\text { Ajudante de } \\
\text { Armador }\end{array}$ & $65,70 \%$ & $4324,00 \%$ & $617,71 \%$ & $1013,44 \%$ \\
\hline
\end{tabular}

Fonte: Autores, (2017).
Diferente do que acontece no serviço de produção de concreto, nota-se que a Empresa D é a que mais se aproxima tanto da média das médias entre as empresas, como dos menores e maiores valores apresentados pelo SINAPI, assim como da média geral entre os mesmos.

No que tange a empresa que mais se distancia dos valores obtidos tanto para as médias das empresas, como para os valores apresentados pelo sistema da CEF, observa-se que a Empresa A é a que mais se condiciona a este critério. Neste caso, esta diferença é evidenciada pelo discrepante valor adotado para o espaçador circular de plástico, onde quando comparado ao menor valor do SINAPI, por exemplo, alcança-se um diferencial de $117000,00 \%$.

\section{III.3 SIMULAÇÃO ORÇAMENTÁRIA}

Como descrito na metodologia deste trabalho e com o objetivo de avaliar de forma contábil as diferenças existentes entre os valores de índice adotados pelas empresas e pelo SINAPI, foram coletados os custos unitários da tabela de referência de composições da Secretaria de Estado de Infraestrutura do Amazonas (SEINFRA-AM), no propósito de aproximar os valores a uma realidade local, conforme apresentado na Tabela 8.

Tabela 8: Custos unitários adotados pela SEINFRA-AM.

\begin{tabular}{|c|c|c|}
\hline \multicolumn{3}{|l|}{ PRODUÇÃO DE CONCRETO } \\
\hline Descrição & Unidade & Custo Unitário \\
\hline Cimento Portland & KG & \begin{tabular}{|l|}
$\mathrm{R} \$$ \\
0,68
\end{tabular} \\
\hline Areia & $\mathrm{M}^{3}$ & \begin{tabular}{|l|}
$\mathrm{R} \$$ \\
49,14
\end{tabular} \\
\hline Brita & $\mathrm{M}^{3}$ & \begin{tabular}{|l|}
$\mathrm{R} \$$ \\
114,59
\end{tabular} \\
\hline Pedreiro & $\mathrm{H}$ & \begin{tabular}{|l|}
$\mathrm{R} \$$ \\
11,96
\end{tabular} \\
\hline Servente & $\mathrm{H}$ & $\begin{array}{l}\mathrm{R} \$ \\
8,84\end{array}$ \\
\hline Betoneira (400 litros) & $\mathrm{H}$ & $\begin{array}{l}\mathrm{R} \$ \\
4,20\end{array}$ \\
\hline \multicolumn{3}{|c|}{ ARMAÇÃO DE ESTRUTURAS DE CONCRETO ARMADC } \\
\hline Descrição & Unidade & Custo Unitário \\
\hline Aço CA-50 & KG & \begin{tabular}{l|}
$\mathrm{R} \$$ \\
4,32
\end{tabular} \\
\hline Arame Recozido $N^{\circ} 18$ & KG & $\begin{array}{l}\mathrm{R} \$ \\
8,50\end{array}$ \\
\hline Espaçador Circular de Plástico & UN & $\begin{array}{l}\mathrm{R} \$ \\
0,10\end{array}$ \\
\hline Armador & $\mathrm{H}$ & $\begin{array}{l}\mathrm{R} \$ \\
8,84\end{array}$ \\
\hline Ajudante de Armador & $\mathrm{H}$ & $\begin{array}{l}\mathrm{R} \$ \\
11,96\end{array}$ \\
\hline
\end{tabular}

Fonte: Autores, (2017).

\section{III.4 ANÁLISE DOS RESULTADOS}

A seguir, apresentam-se por intermédio das Figuras 3 e 4, de forma contábil, e das Tabelas 9 e 10, de forma percentual, os resultados obtidos através da simulação orçamentária com os custos unitários adotados pela SEINFRA, onde destacam-se as diferenças entre os insumos, discriminados em materiais, mão de obra e equipamentos, assim como do custo total. 


\section{III.4.1 PRODUÇÃO DE CONCRETO}

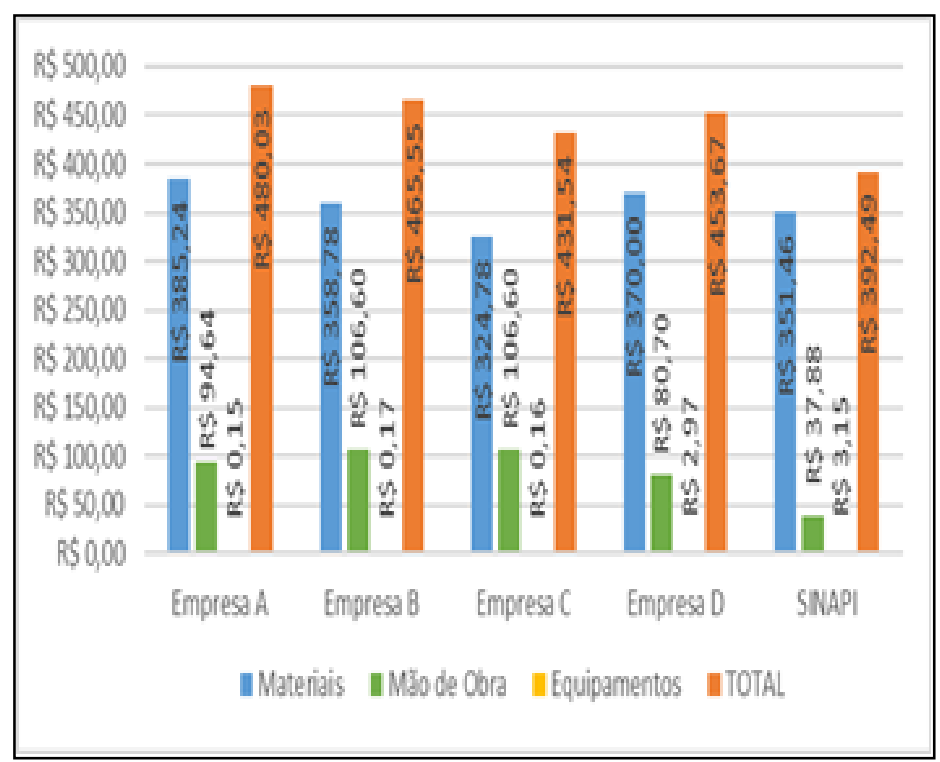

Figura 3: Análise contábil entre os custos das empresas e do SINAPI (Produção de Concreto).

Fonte: Autores, (2017).

Tabela 9: Análise percentual entre os custos das empresas e do SINAPI (Produção de Concreto).

\begin{tabular}{|l|l|l|l|l|}
\hline SINAPI & Materiais & $\begin{array}{l}\text { Mão de } \\
\text { Obra }\end{array}$ & Equipamentos & TOTAL \\
\hline Empresa A & $109,61 \%$ & $249,84 \%$ & $4,76 \%$ & $\mathbf{1 2 2 , 3 0 \%}$ \\
\hline Empresa B & $102,08 \%$ & $281,41 \%$ & $5,40 \%$ & $\mathbf{1 1 8 , 6 1 \%}$ \\
\hline Empresa C & $92,41 \%$ & $281,41 \%$ & $5,08 \%$ & $\mathbf{1 0 9 , 9 5 \%}$ \\
\hline Empresa D & $105,28 \%$ & $213,04 \%$ & $94,29 \%$ & $\mathbf{1 1 5 , 5 9 \%}$ \\
\hline
\end{tabular}

Fonte: Autores, (2017).

Para os insumos referentes aos materiais, os índices não provocam diferenças significativas para as empresas, onde a divergência máxima entre os valores corresponde a 109,61\% do proposto pelo SINAPI. Porém, nos insumos de mão de obra e equipamentos, observa-se que o primeiro apresentou a maior diferença percentual, cerca de $281,41 \%$ do valor da CEF (Empresas B e C), enquanto o segundo corresponde a $4,76 \%$ (Empresa A).

Nota-se também, quando comparadas aos valores de insumo do SINAPI, as empresas apresentam valores relativamente próximos, exceto no que se trata aos valores de equipamentos referentes à Empresa D, onde há uma expressiva diferença em relação às demais.

Por fim, ao analisar o custo total do serviço, percebe-se que a diferença máxima trata de $122,30 \%$ do valor apresentado pelo SINAPI (Empresa A).

\section{III.4.2 ARMAÇÃO DE ESTRUTURAS DE CONCRETO ARMADO}

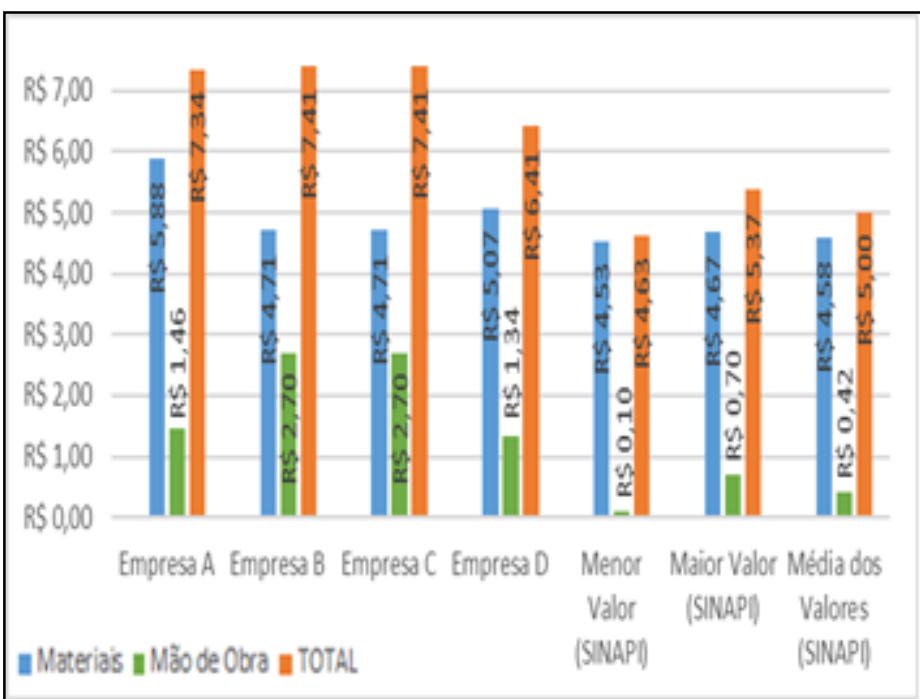

Figura 4 - Análise contábil entre os custos das empresas e do SINAPI (Armação).

Fonte: Autores, (2017).

Tabela 10 - Análise percentual entre os custos das empresas e do SINAPI (Armação).

\begin{tabular}{|c|c|c|c|}
\hline \multirow[b]{2}{*}{ Empresa A } & \multicolumn{3}{|l|}{ SINAPI } \\
\hline & Menor Valor & $\begin{array}{l}\text { Maior } \\
\text { Valor }\end{array}$ & Média Geral \\
\hline Material & $129,80 \%$ & $125,91 \%$ & $128,38 \%$ \\
\hline Mão de Obra & $1460,00 \%$ & $208,57 \%$ & $347,62 \%$ \\
\hline TOTAL & $158,53 \%$ & $136,69 \%$ & $146,80 \%$ \\
\hline Empresa B & $\begin{array}{l}\text { SINAPI } \\
\text { Menor Valor }\end{array}$ & $\begin{array}{l}\text { Maior } \\
\text { Valor }\end{array}$ & Menor Valor \\
\hline Material & $103,97 \%$ & $100,86 \%$ & $102,84 \%$ \\
\hline Mão de Obra & $2700,00 \%$ & $385,71 \%$ & $642,86 \%$ \\
\hline TOTAL & $160,04 \%$ & $137,99 \%$ & $148,20 \%$ \\
\hline Empresa C & Menor Valor & $\begin{array}{l}\text { Maior } \\
\text { Valor }\end{array}$ & Média Geral \\
\hline Material & $103,97 \%$ & $100,86 \%$ & $102,84 \%$ \\
\hline Mão de Obra & $2700,00 \%$ & $385,71 \%$ & $642,86 \%$ \\
\hline TOTAL & $160,04 \%$ & $137,99 \%$ & $148,20 \%$ \\
\hline Empresa D & $\begin{array}{l}\text { SINAPI } \\
\text { Menor Valor }\end{array}$ & $\begin{array}{l}\text { Maior } \\
\text { Valor }\end{array}$ & Menor Valor \\
\hline Material & $111,92 \%$ & $108,57 \%$ & $110,70 \%$ \\
\hline Mão de Obra & $1340,00 \%$ & $191,43 \%$ & $319,05 \%$ \\
\hline TOTAL & $138,44 \%$ & $119,37 \%$ & $128,20 \%$ \\
\hline
\end{tabular}

Fonte: Autores, (2017). 
Quanto ao serviço de armação de estruturas de concreto armado, também se percebe que não há diferenças significativas entre os custos das empresas e dos menores e maiores valores do SINAPI, assim como da média geral. Neste caso, em relação aos valores da CEF, a maior diferença percentual corresponde a $129,80 \%$ do menor valor, $125,91 \%$ do maior e $128,38 \%$ da média geral (Empresa A).

No que se refere à mão de obra, observa-se que há uma expressiva diferença entre os valores das empresas e do SINAPI, retratada nos $2700,00 \%$ do menor valor, $385,71 \%$ do maior e $642,86 \%$ da média geral, referentes às Empresas B e C.

Quando analisado o custo total do serviço, percebe-se que as Empresas B e C também apresentam os maiores custos, onde $160,04 \%$ correspondem ao menor valor, $137,99 \%$ ao maior e $148,20 \%$ à média geral.

\section{CONCLUSÃO}

Com base nos resultados obtidos através dos estudos comparativos e simulações orçamentárias, foi possível avaliar a utilização dos índices do SINAPI, para a elaboração de orçamentos de obras na cidade de Manaus, no tocante às composições de materiais, mão de obra e equipamentos dos serviços de produção de concreto e armação de estruturas de concreto armado.

Verificou-se, através da presente pesquisa, que no caso do SINAPI, os índices do serviço de armação de estruturas de concreto armado que proporcionam um maior impacto no ponto de vista econômico, são os que mais se aproximam da realidade das empresas de Manaus, onde o serviço é considerado para todas as bitolas e aplicações estruturais (lajes, vigas e pilares).

Quanto aos insumos de mão de obra e equipamentos, verificou-se uma significativa diferença, que pode ter como origem os diferentes processos construtivos existentes nas regiões do Brasil e dessa forma, é necessária uma maior análise dos processos de aferição dos coeficientes das empresas e do SINAPI.

Portanto, conclui-se que a utilização das tabelas do SINAPI para a cidade de Manaus apresenta-se como viável no que diz respeito aos materiais. Porém, no que se refere à mão de obra e equipamentos, a condição de viabilidade não é verdadeira, pois conforme os resultados apresentados nesta pesquisa, o orçamento com uso dos coeficientes da CEF pode não representar a realidade executiva do serviço, resultando em prejuízo em relação ao tempo e ao custo total.

\section{REFERÊNCIAS}

[1] MATTOS, A. D. Planejamento e controle de obras. São Paulo: Editora PINI, 2010. 420 p.

[2] ALVES, G. S.; ARAÚJO, N. M. C. Composições de custos unitários: TCPO X Apropriação in loco. João Pessoa, PB, 2010. Acesso em 18/ 12/ 2017. Disponível em:< http://www.congressos.ifal.edu.br/index.php/connepi/CONNEPI2 $\underline{010 / \text { paper/viewFile/1548/756> }}$

[3] LOSSO, Iseu Reichmann. Utilização das características geométricas da edificação na elaboração preliminar de custos: estudo de caso em uma empresa de construção civil. 1995. 146 p. Dissertação (Mestrado em Engenharia Civil). PPGEC, UFSC, Florianópolis, 1995.
[4] MATTOS, A. D. Como preparar orçamentos de obras: dicas, estudos de caso, exemplos. São Paulo: Editora PINI, 2006. $281 \mathrm{p}$.

[5] MAÇAHIKO, T. Orçamento na construção civil: consultoria, projeto e execução. São Paulo: Editora PINI, 2006.

[6] BRASIL, Caixa Econômica Federal. SINAPI - Sistema Nacional de Pesquisas de Custos e Índices da Construção Civil. Disponível em: <http://www.caixa.gov.br/poderpublico/apoio-poder-publico/sinapi/Paginas/default.aspx.>

Acesso em: out. 2017.

[7] SINAPI: Cadernos técnicos de composições para armação de estruturas de concreto armado. Lote 1, versão 006. 2017.

[8] _. SINAPI: Cadernos técnicos de composições para produção de concreto. Lote 1, versão 004. 2017.

[9] SINAPI: Metodologias e conceitos. Fev, 2017. 169 p.

[10] GEHBAUER, F. et al. Planejamento e gestão de obras: um resultado prático da coordenação técnica Brasil-Alemanha. Curitiba: CEFET-PR, 2002. 520 p.

[11] LAKATOS, E. M. Fundamentos de metodologia científica. São Paulo: Editora Atlas, 2003.

[12] THOMAZ, E. Tecnologia, gerenciamento e qualidade na construção. São Paulo: Editora PIN 